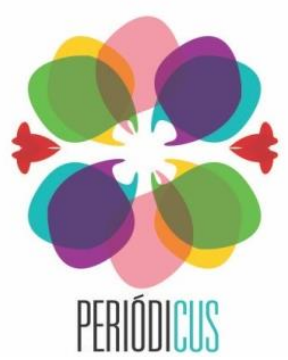

ISSN: 2358-7844

п. 14. v. 1 nov.2020-abr.2021 р. $160-183$.

\title{
Entrelaçamentos entre religião e
} diversidade sexual e de gênero: análise do discurso de cristãs/ãos brasileiras/os

(Interweavings between religion and sexual and gender diversity: discourse analysis of Brazilian Christians)

(Entrelazamientos entre religión y diversidad sexual y de género: análisis del discurso de cristianas/os

brasileñas/os)

\section{Anderson Moraes Pires ${ }^{1}$}

RESUMO: O objetivo central deste artigo é observar qual o posicionamento predominante de pessoas que se aproximam, a partir de seus discursos, da cis-heteronormatividade e das concepções de religiões cristãs frente à diversidade sexual e de gênero no território brasileiro. Utilizou-se vídeos públicos disponíveis no YouTube e a análise foi orientada por Análise do Discurso. As discussões foram feitas a partir das categorias: a. a cisheteronormatividade: regulação de saberes e práticas; b. religiões cristãs: presença na mídia e na política; e c. LGBTQIAfobia e subjetividades dissidentes. Considerou-se que as características exclusivamente biológicas ainda conseguem definir e determinar os modos de existências das pessoas, desconsiderando o gênero, por exemplo, como uma construção social.

PALA VRAS-CHAVE: Diversidade sexual. Religião. LGBTQIA+. Evangélicos. Católicos.

\begin{abstract}
The main objective of this article is to observe the predominant stance of people who approach cisheteronormativity and the conceptions of Christian religions regarding sexual and gender diversity in Brazilian territory via their discourse. Public videos available on YouTube were used and the analysis was guided by Discourse Analysis. Discussions were made about the categories: a. cis-heteronormativity: regulation of knowledge and practices; b. Christian religions: presence in the media and politics; and c. LGBTQIAphobia and dissident subjectivities. Exclusively biological characteristics were shown to still be able to define and determine people's modes of existence, disregarding gender, for example, as a social construction.
\end{abstract}

Keywords: Sexual diversity. Religion. LGBTQIA+. Evangelicals. Catholics.

Resumen: El objetivo principal de este artículo es observar el posicionamiento predominante de las personas que se acercan, desde sus discursos, a la cisheteronormatividad y las concepciones de las religiones cristianas con respecto a la diversidad sexual y de género en el territorio brasileño. Se usaron videos públicos disponibles en YouTube, y el análisis fue guiado por el Análisis del Discurso. Se discutieron las categorías: a) cisheteronormatividad: regulación de conocimientos y prácticas; b) Religiones cristianas: presencia en los medios y en la política; y, c) LGBTQIAfobia y subjetividades disidentes. Se consideró que las características exclusivamente biológicas todavía pueden definir y determinar los modos de existencia de las personas, sin tener en cuenta el género, por ejemplo, como una construcción social.

Palabras clave: Diversidad sexual. Religión. LGBTQIA+. Evangélicos. Católicos.

1 Universidade Federal do Ceará. E-mail: andeersonpires@gmail.com. 
Sua lei me tornou ilegal. Me chamaram de suja, louca e sem moral.

(Diaba, Urias)

\section{Introduçãa}

A diversidade sexual é entendida neste artigo, e em todos os estudos utilizados como referência, como várias formas de expressão e vivência sexual. O sexo biológico, a orientação sexual e a identidade de gênero são os elementos mais utilizados nas discussões, fazendo-se refletir sobre as questões biológicas, psicológicas e sociais. O gênero, especificamente, é uma construção social que se opõe à ideia de sexo biológico, ou seja, os homens e as mulheres, em uma lógica binária de gênero, são produtos de uma realidade social, vista a partir de uma divisão ocidente versus oriente, norte ou sul, nordeste brasileiro ou sudeste brasileiro, entre outras.

As inúmeras divisões territoriais e/ou socioculturais podem suscitar questões que se relacionam com as diversidades sexuais e de gêneros. É neste sentido, por exemplo, que se destaca que o território nacional sempre foi rico para as práticas religiosas, ou melhor, para a disseminação de saberes de religiões da fé cristã. Magali do Nascimento Cunha (2019) explica que foi, principalmente, a partir de 2010 que os evangélicos ${ }^{2}$ brasileiros conseguiram juntar um corpo expressivo à medida que estabeleceram estreitas relações com as mídias digitais, com a internet, e com a política. O trabalho dessas pessoas na internet foi gradual, assim como a maioria das atividades realizadas sem coordenação; não havia regra, como não há até hoje, no sentido de manuais de 'como fazer uma revolução utilizando a tecnologia'. Já a atuação na política, na concepção da autora, foi desenvolvida através de projetos sociais, tendo o poder público como parceiro, exigindo, dessa forma, uma melhor capacitação em temas de interesse da maioria das/os 'irmãs/ãos', das/os cidadãs/ãos.

Anterior à presença e forte influência das personalidades evangélicas, as pessoas católicas administravam um campo midiático e social religioso mais homogêneo. Este campo foi minando a partir das ações exemplificadas anteriormente e, por isto, podem ser entendidas como efetivas. Além disso, as pessoas evangélicas passaram a promover grandes eventos, como por exemplo a

2 Considera-se, neste artigo, 'evangélicos' as pessoas dos diferentes movimentos protestantes aqui do Brasil, a exemplo das/os frequentadoras/es das Assembleias de Deus, das Igrejas Batistas, da Igreja Universal do Reino de Deus, entre outras. Destaca-se que há ramificações, e 'evangélicos' está ao longo deste texto como um termo guarda-chuva. Ainda é importante expor que dentro da multifacetação dessas igrejas, existem as 'igrejas inclusivas', que adotam políticas acolhedoras com as minorias. Ver mais informações em Alexandre (2014). 
Marcha para Jesus, na cidade de São Paulo, que é realizada no mesmo dia de um grande feriado católico, conseguindo grandes números de participantes. (CUNHA, 2019)

Apesar das diferenças entre católicos e evangélicos, sabendo que ainda tem diversas diferenciações dentro de cada categoria, as subjetividades das/os LGBTQIA ${ }^{3}{ }^{3}$ podem ser atravessadas de formas não tão distintas por estes grupos, por se apoiarem no cristianismo. Por isto, destacam-se neste trabalho as aproximações discursivas de pessoas que se apresentam dentro desses segmentos, sem realçar, necessariamente, as suas diferenças.

Perceber o processo da 'religião pública', como vem acontecendo, é o mesmo que considerar que as religiões estão em um campo, ou em vários campos, de disputa pelo horizonte, pela garantia da homogeneidade, seja de corpos, práticas e/ou subjetividades. Este processo da religião pública se dá através de sua constituição como cultura e como discurso sobre valores, que só é possível se existir a projeção para além da fronteira do privado, considerando as vivências pessoais e coletivas, de formas institucionais e/ou informais. (CUNHA, 2019)

Todo este escopo remete à saberes e práticas que conseguem manipular grandes decisões públicas sociais. Sendo assim, é importante saber o que as pessoas que se apresentam dentro de alguma religião da fé cristã pensam e fazem para colaborar com a garantia ou aniquilamento da vida das pessoas LGBTQIA+, seja no sentido literal ou no sentido figurado. Então, não se pode somente fechar a porta e apagar as luzes ou desconectar a internet e bloquear os aparelhos. É necessário, enquanto cidadãs/ãos, verificar se os interesses privados interferem negativamente no espaço público, na construção e na expressão de sexualidades e de gêneros.

De acordo com Michel Foucault (1996, p. 9): "Em toda sociedade a produção do discurso é ao mesmo tempo controlada, selecionada, organizada e redistribuída por certos procedimentos que têm por função conjurar seus poderes e perigos". Ou seja, os discursos que aqui serão analisados têm, assim como outros não citados, uma função socialmente organizativa.

Sendo assim, este trabalho segue uma trilha construída de acordo com a necessidade dos próprios resultados, fazendo com que a primeira discussão seja acerca da cisbissexuais e trans. $\mathrm{O}$ termo trans refere-se às pessoas que se identificam como travestis, transexuais e transgêneros. No entanto, foi considerado o uso de LGBTQIA+ para demonstrar a existência de outras orientações sexuais, identidades de gênero e usos dos corpos. O símbolo + como uma pluralidade e diversidade, e não como "o resto das identidades que não couberam na sigla”. 
heteronormatividade ${ }^{4}$, a partir de uma possível lógica cristã. Desconsiderando, neste momento, todas as características constitutivas e normativas, a cis-heteronormatividade é produtora cultural das diferenças homem-mulher e das diferenças cis-trans, é uma "naturalização, fundada sobre preceitos evolucionistas". (MATTOS; CIDADE, 2016, p. 135)

As regulações das diversidades de gêneros e de sexualidades, ancoradas na cisheteronorma, faz com que exista, de acordo com Natividade (2013), uma demonização da diversidade, que no âmbito escolar, por exemplo, seja falado sobre uma 'educação da besta' e uma 'educação de Deus'. Já se percebe, a partir disso, uma possível colaboração moral com fundamentos advindos do ensino cristão religioso.

As possíveis problematizações dos atravessamentos subjetivos, em específico, das violências simbólicas causadas às pessoas LGBTQIA+, convergem com a complexa relação existente entre religiões cristãs, mídia e política, sabendo que os 'discursos de verdade' 5 circulam nessas relações e conseguem ditar o cotidiano de uma forma muito bem articulada e imperceptível, se feita sem reflexões críticas. As problematizações são vistas como uma possibilidade, pois se entende que pode não existir violências simbólicas. Aqui no Brasil, as Igrejas Inclusivas estão bem mais distribuídas, além das inúmeras pastorais que existem a partir das próprias pessoas LGBTQIA+.

Portanto, o objetivo geral deste artigo é observar qual o posicionamento predominante de pessoas que se aproximam, a partir de seus discursos, da cis-heteronormatividade e das concepções de religiões cristãs frente à diversidade sexual e de gênero no território brasileiro. Para isto, especificamente, buscou-se compreender se a cis-heteronormatividade, com colaboração da moral religiosa, é reguladora dos saberes e práticas; analisar as relações das religiões da fé cristã no espaço midiático e político; e, por fim, problematizar como as subjetividades das pessoas LGBTQIA+ são atravessadas pelos discursos dessas pessoas.

4 Neste artigo, a perspectiva 'cis-heteronormativa' “tem a matriz heterossexual como base das relações de parentesco e a matriz cisgênera como organizadora das designações compulsórias e experiências das identidades de gênero". (MATTOS; CIDADE, 2016, p. 134) Ou seja, a heteronorma marginaliza as orientações sexuais que são diferentes da heterossexual e a cisnorma favorece as pessoas que são vistas como 'alinhadas' em relação aos seus corpos e gêneros.

5 Este conceito foucaultiano refere-se às verdades construídas historicamente que estabelecem relações de poder, como por exemplo a concepção de que o agrupamento institucional (familiar) de um homem, uma mulher e filhas/os é a única forma legítima e 'normal' de se fazer família, sendo entendida como monogâmica, heterossexual e patriarcal. A relação de poder é vista na hierarquização que faz com que a mulher (esposa) e as/os filhos sejam submissas/os ao homem. Sobre 'discurso de verdade', ver: Michel Foucault (1996). 
A relevância de escolher os discursos disponíveis no YouTube pode ser justificada através dos estudos de Pellegrini et al. (2009), pois as/os autoras/es dizem que as pessoas são seres imagéticos, são intrinsecamente ligadas às imagens, logo mais facilmente influenciadas. Além disso, o YouTube, que é uma 'terra sem dona/o', tem servido de fonte de imagens para a televisão. Ou seja, conseguiu que o nome do canal se aproximasse da realidade: you — você; tube - tubo/televisão. Então, os materiais não estão restritos à pólis midiática, podendo entrar em lugares que não possuem acesso à internet, além de existir um entrelaçamento entre os conteúdos das diversas plataformas digitais.

A plataforma digital citada possui mais de dois bilhões de usuários cadastrados, correspondendo a quase um terço da internet - sabendo que ainda é possível ter acesso aos materiais mesmo sem cadastro. Além disso, todos os dias são assistidas mais de um bilhão de horas, que são distribuídas entre os inúmeros documentos publicados por pessoas amadoras e profissionais, pessoas que possuem formações técnicas e por pessoas que não entendem a complexidade tecnológica; que acreditam, de alguma forma, no slogan do site: broadcast yourself, 'divulgue-se'. (YOUTUBE, 2020)

\section{Percurso metodológico}

Este estudo possui caráter qualitativo, objetivando-se emergir aspectos subjetivos e não, necessariamente, numéricos. $\mathrm{O}$ estudo começou com a observação dos dez primeiros vídeos no YouTube, encontrados a partir da busca ${ }^{6}$ : 'LGBT religião'. A escolha das palavras pesquisadas não seguiu um padrão metodologicamente estabelecido, a intenção foi simular a experiência de alguém que tem acesso à plataforma para encontrar vídeos que relacione os dois temas ou similares, da maneira mais simplificada possível. E, a sigla 'LGBT' foi escolhida pois ainda é a mais usada em grandes veículos de comunicação e eventos, a exemplo da Parada do Orgulho LGBT de São Paulo.

Como critério metodológico, foi selecionado, entre os dez primeiros vídeos, todos que possuíam: a. pessoas que mais se aproximaram da cis-heteronormatividade; b. pessoas que utilizaram as concepções da fé cristã para apresentar alguma ideia; e c. vídeos em português. Não houve restrições quanto ao tempo de duração do vídeo ou ao ano de sua publicação. A escolha

6 Esta busca foi realizada no dia 12 de abril de 2020. O YouTube possui um mecanismo que entrega os resultados de acordo com a relevância do vídeo naquele momento, além de relacionar com a conta da/o usuária/o. Então, este resultado é constantemente modificado. 
desses materiais foi influenciada pelo caráter público da plataforma, compreendendo que são os próprios produtores dos conteúdos que escolhem os temas a serem discutidos com os seguidores de suas páginas e os demais usuários que não são cadastrados, 'inscritos'.

Em conformidade com Rita Caregnato e Regina Mutti (2006), a análise do discurso busca os efeitos de sentido que se pode apreender mediante interpretação, sabendo que esta interpretação discursiva tem influência dos afetos, da posição, das crenças e experiências de quem pesquisa. As autoras destacam que "a interpretação sempre é passível de equívoco, pois embora a interpretação pareça ser clara, na realidade existem muitas e diferentes definições, sendo que os sentidos não são tão evidentes como parecem ser”. (CAREGNATO; MUTTI, 2006, p. 682) Por isto, após a seleção dos vídeos, considerou-se a necessidade de um longo período de familiaridade com os vídeos e foram feitas anotações em um diário de campo, transcrições dos áudios sem auxílio de software e observação sistemática dos vídeos que se relacionavam com o objetivo do artigo.

O levantamento bibliográfico foi importante para aproximar este artigo com as principais argumentações de autoras e autores que contribuem nas questões de diversidade de gêneros e sexualidades no campo religioso. No entanto, não se busca encontrar respostas definitivas ou produzir verdades de caráter absolutas. (ANTUNES, 2016) Por isto, à luz da perspectiva adorniana, as análises dos discursos encontram-se simultaneamente com o referencial teórico.

Além disso, os cuidados éticos deste estudo seguem a resolução ${ }^{0}$ 510/2016 do Comitê de Ética, que é amparada pela Lei de Acesso à Informação ( $\left.{ }^{\circ} 12.527 / 2011\right)$, fazendo com que o tratamento das informações pessoais seja realizado de maneira transparente e com respeito à vida privada, honra e imagem das pessoas. (BRASIL, 2011)

Como já dito, o YouTube recebe um número extenso de materiais audiovisuais sobre diversos temas e não disponibiliza, em sua interface, a quantidade total do resultado. Por isto, para atender aos objetivos da melhor forma possível, restringiu-se a quantidade de vídeos analisados, selecionando os 10 primeiros vídeos caso atendessem aos critérios de inclusão.

Os vídeos 1 e 3 da busca 'LGBT religião' são produções de um homem cis homossexual, de acordo com a sua própria apresentação, autodefinição; e o resultado 2 é um vídeo de um médico especializado em oncologia. Estes três vídeos não foram considerados para a análise deste artigo, pois os autores não se aproximam da cis-heteronormatividade e/ou das concepções da fé cristã para apresentar as suas ideias. O resultado 5 é uma playlist, uma lista com outros 
diversos vídeos, por isso também foi desconsiderada. A seleção final contou com seis vídeos elegíveis. Para tanto, foram elaboradas abreviações dos títulos para melhor realizar as discussões, de acordo com a sequência dada pelo próprio site.

As três categorias a seguir emergiram após análise detalhada dos vídeos: a cisheteronormatividade: regulação de saberes e práticas; religiões cristãs: presença na mídia e na política; e, LGBTQIAfobia e subjetividades dissidentes ${ }^{7}$.

\section{A Cis-heteronormatividade: regulação de saberes e práticas}

As características exclusivamente biológicas ainda conseguem definir e determinar os modos de existências das pessoas, a exemplo de como 'ser' mulher ou homem. Segundo Silva, Pereira e Pontes (2019), essa categorização e outras similares são sustentadas pela lógica cisheteronormativa de matriz hegemônica, que busca produzir binarismo sexual e identitário, em que cada corpo só tem um único direito constitutivo, sendo o masculino ou feminino.

Ainda na lógica dos autores e da autora citados/a, as identidades masculinas, por exemplo, são condicionadas desde muito cedo, e até mesmo antes do nascimento das crianças, a dar continuidade ao legado que carrega características machistas, patriarcais e misóginas, com a finalidade de manter a virilidade e todos os outros traços compartilhados. Sendo assim, este funcionamento cis-heteronormativo compactua com o aniquilamento identitário das pessoas que não se encaixam nessa lógica e marginalizam os corpos dissidentes.

O vídeo Existe “cura gay”? Padre Paulo Ricardo responde (EXISTE..., 2018) foi publicado em maio de 2018 e está no próprio canal do Padre Paulo Ricardo. Este canal tem mais de 942 mil inscritos, 143.964 .709 visualizações ${ }^{8}$ e, de acordo com a sua própria descrição, tem tudo o que uma pessoa católica precisa saber ${ }^{9}$. Além disso, há a informação de que todo o material publicado é em conformidade com a doutrina de dois mil anos da Santa Igreja Católica. O vídeo a ser discutido apresenta 111.640 visualizações. Vale destacar estes números para buscar dimensionar a quantidade de pessoas que já tiveram contato com essas informações.

7 A expressão 'dissidentes', 'dissidências' e similares são utilizadas para remeter-se a uma ideia de diversidade sexual e de gênero, ou seja, ao que se contrapõe às normativas cis-heterossexuais hegemônicas.

8 Os números de visualizações/acessos e inscritos foram coletados no dia 29 de maio de 2020.

9 Descrição disponível em: Padre Paulo Ricardo: Christo Nihil Praeponere (PADRE..., 2010). 
O vídeo dialoga com a concepção normativa de expressões identitárias mencionadas no início deste tópico, tal como se apresenta na seguinte narrativa, logo após mencionar que seria uma grande discriminação contra os homossexuais se a santidade também não fosse possível para eles: "Então eu tenho aqui um relacionamento de um homem e de uma mulher. Os dois estão na família, eles têm filhos, eles podem ser santos". (EXISTE..., 2018, grifo nosso)

O autor do vídeo acredita que todas as pessoas podem ser santas. No entanto, para tal afirmação, buscam-se referências de configurações familiares baseadas em um modelo cisheterossexual, no qual o homem, a mulher e os/as filhos/as têm suas 'funções' já definidas. Pode-se compreender em muitos momentos do vídeo que somente os heterossexuais cisgêneros podem ser 'santos', além de compreender que são eles quem podem constituir uma 'família'. A fim de melhor contextualizar a narrativa apresentada, nota-se que, em sua totalidade, ela se apresenta contraditória.

A dificuldade para perceber como o funcionamento cis-heteronormativo presente no discurso do vídeo Existe “cura gay”? Padre Paulo Ricardo responde, em específico, é capaz de marginalizar as pessoas que são contra as vias hegemônicas é posta ao passo que o autor do vídeo tece seus argumentos pela perspectiva quase exclusiva da prática sexual e toma a discussão igualando as experiências, 'somos todos iguais', da seguinte maneira: "a cura gay é a mes- é igual a cura hétero, que é igual a cura bissexual, que é igual a cura transsexual, que é igual... qualquer outra cura que se chama santidade”. (EXISTE..., 2018)

Como o narrador do vídeo fala sobre os homossexuais, é importante saber que os homens gays, ou bichas e bixas ${ }^{10}$ afeminadas exercem vários papéis sociais e um deles é o de quebrar com a hegemonia da masculinidade. Esses sujeitos ainda se adequam ao cistema, termo que remete-se ao sistema da cisgeneridade, porém se aproximam de características que o social entende como feminino, causando repulsa. Dessa forma, eles ultrapassam as barreiras da heteronormatividade. E é por isto, ainda na concepção de Silva, Pereira e Pontes (2019, p. 11), que "esses homens gays são submetidos a situações de violência e afeminofobia que marginalizam seus corpos e apagam suas identidades em detrimento de um padrão estruturante dicotômico". No entanto, para entender essas situações de violência de uma forma mais satisfatória, o último tópico discursivo deste artigo apresenta as 'sutilezas' e 'cordialidades' das falas e práticas LGBTQIAfóbicas.

$10 \mathrm{O}$ termo bixa é colocado neste trabalho a fim de remeter-se às bixas pretas que Lucas Veiga apresentou em sua publicação (VEIGA, 2018). 
Para exemplificar como as relações de gêneros e sexualidades são complexas, faz-se necessário apresentar a machonormatividade, que é tida como uma ideologia e prática que busca e consegue rejeitar as mulheres trans e cis, as travestis, as bichas e bixas afeminadas, bem como os homens trans e cis heterossexuais afeminados. (SILVA; PEREIRA; PONTES, 2019) Nesse sentido, pode-se perceber que o sistema cisgênero ainda estabelece repulsa ao feminino, permitindo que o topo da hierarquia seja ocupado somente por quem possui pênis e seja macho, ou seja, por quem é 'homem de verdade'.

Com esta discussão é importante destacar que os papéis dos homens cisgêneroheterossexuais-brancos são colocados acima das demais pessoas, facilitando uma demarcação de lugares de onde as relações de poder são favoráveis para, principalmente, os machos que sustentam suas machonormatividades. (SILVA; PEREIRA; PONTES, 2019)

O modo binário relacionado com a cis-heteronormatividade de compartilhar as experiências, ou seja, o modo que considera apenas masculino ou feminino, faz com que os homens gays devem ter o futebol como uma atividade essencial a fim de restaurar a heterossexualidade, ao passo que as mulheres lésbicas são incentivadas a exercer atributos considerados naturalmente femininos do cuidado e da docilidade, como por exemplo cozinhar, lavar e passar. (NATIVIDADE, 2008 apud NATIVIDADE, 2013)

Diante do exposto, das complexas relações sociais que envolvem gêneros e sexualidades, Natividade consegue melhor explicar que:

\begin{abstract}
Esta construção de uma conexão naturalizada entre 'sexo', 'gênero', 'desejo' e 'práticas' heterossexuais requer uma desqualificação de formas de vivência da sexualidade e do gênero que sejam dissidentes da norma heterossexual. Toda construção do gênero e do desejo que seja destoante desta norma é marcada como uma diferença indesejável, que ameaça as fantasias de identidade cultivadas por alguns sujeitos que entendem que a humanidade inteira 'é' (ou pelo menos "deveria ser") heterossexual. (NATIVIDADE, 2013, p. 46)
\end{abstract}

Já este regime heteronormativo, como cita Marcelo Natividade e Leandro de Oliveira (2018, p. 69), tem a colaboração do "conservadorismo católico e evangélico, que obstrui as demandas por reconhecimento de populações não heterossexuais". Este não reconhecimento pode ser lido como, no mínimo, mortes simbólicas, que podem ocorrer de forma lenta e imperceptível aos olhos de muitas pessoas. Referir-se aos dissidentes, ou diferentes, da cisheteronormatividade por termos pejorativos, como muito se tem feito na história do Brasil, pode fazer com que as pessoas não heterossexuais e trans neguem suas próprias sexualidades e identidades e que se isolem dos seus grupos. 
Segundo Magali Cunha (2019, p. 9), os/as evangélicos/as brasileiros/as, independente das peculiaridades, foram identificados "por frequentes posturas de rejeição das manifestações culturais não cristãs do País". A autora ainda acrescenta que existe uma leitura fundamentalista, literal, do texto sagrado cristão. Neste sentido, pode-se observar que os/as autores/as dos vídeos analisados partem desta leitura mencionada por Cunha (2019).

O vídeo Os cristãos e os homossexuais (OS CRISTÃOS..., 2014) foi publicado em fevereiro de 2014, no canal da jornalista Fabiana Bertotti, que não apresenta uma descrição disponível na plataforma, mas no último ano teve a discussão predominante acerca de maternidade e casamento. O canal teve início em março de 2009, tem mais de 616 mil inscritos e 34.637 .832 visualizações.

A autora não especificou na introdução do vídeo qual seria o seu objetivo, mas após uma breve apresentação do seu livro, apresentou, e já se posicionou contrária, ao caso de uma mãe que expulsou a filha lésbica em nome do amor à igreja e à sociedade. A narradora, mesmo demarcando sua posição contrária à discriminação, afirma que "Eu não apoio homem transar com homem, mulher casar com mulher. Pelo simples fato de que eu sigo a bíblia e a bíblia diz que é pecado". (OS CRISTÃOS..., 2014) Após outras maneiras de falar sobre o tema, a autora 'simplifica' sua mensagem: "a bíblia não apoia prática homossexual, de relação homossexual”. (OS CRISTÃOS..., 2014)

Além deste vídeo, há contribuições de Leandro Quadros, que utiliza uma interpretação literal da bíblia. O criador do vídeo pretende, em seu canal, dar respostas para as dúvidas bíblicas, aconselhar e fazer comentários. (LEANDRO..., 2009) Sua página foi inscrita no YouTube em outubro de 2009 e atualmente está com 403 mil inscritos e 31.562.427 visualizações. O seu vídeo intitulado A religião e a Bíblia são contra os LGBT? - Leandro Quadros - IASD (A RELIGIÃO.., 2019), publicado em janeiro de 2019 e com 5.429 visualizações, apresenta as seguintes afirmações:

\footnotetext{
Existe muito preconceito para com os religiosos, em relação a este aspecto. Mas obviamente existe o preconceito por parte de alguns religiosos. Porém eu quero mostrar pra você o que a bíblia diz a respeito e você vai perceber que em essência a bíblia não é contra o homossexual. A bíblia se posiciona contra o comportamento homossexual, que são coisas bem diferentes. (A RELIGIÃO..., 2019)

Quando o cristianismo se posiciona contra o comportamento homossexual, o cristianismo tem pressuposto Gênesis [...] e tem como propósito mostrar o plano de Deus para a sexualidade humana. Em gênesis $[\ldots]$ lemos que quando Deus cria a humanidade, Ele cria o relacionamento heterossexual, como parte daquela normalidade de relacionamentos que Deus criou para serem assim. Afinal, o sexo, ele não foi dado por Deus apenas para o prazer. (A RELIGIÃO..., 2019, grifo nosso)
} 
A afirmação de uma demasiada leitura fundamentalista dialoga com o argumento de Natividade (2013) que sustenta que alguns discursos religiosos na esfera pública, entendo aqui o YouTube como um espaço público, são fundamentados por concepções morais, estereótipos e percepções que estigmatizam a suposta inferioridade da diversidade sexual, contrapondo-se com as definições rituais de santidade, pecado e pureza.

Entendendo que há religiosos que são contra toda manifestação que não dialoga com os textos bíblicos tais como foram escritos há séculos, Marcelo Natividade (2013) cita que discursos de religiosos ajudaram o corpo social a fazer uma associação direta entre pedofilia e homossexualidade, além de manipular estereótipos acerca da epidemia de HIV/Aids, nos anos 1980. Nesse cenário, fortaleceu-se o imaginário de que a doença era um castigo divino e que era exclusiva de homossexuais masculinos e, posteriormente, de travestis e transsexuais, causando, inclusive, um pânico moral em nome da 'ordem'.

No vídeo $O$ homossexualismo e a ideologia gay (O HOMOSSEXUALISMO..., 2011), com 147.528 visualizações, publicado por Padre Paulo Ricardo, em maio de 2011, é possível perceber a construção argumentativa contra os movimentos sociais que buscam a garantia de direitos das pessoas LGBTQIA+. Ou seja, o autor opõe-se à manifestação que não dialoga com a sua interpretação bíblica, tal como argumentou Natividade (2013). No vídeo é citado, em específico, um grupo de 'ideologia gay', composto por homossexuais masculinos e pessoas que lutam pelos direitos LGBTQIA+. O padre afirma que "essas pessoas que se engajam nesse tipo de luta terminam se contaminando de aids, drogadas, terminam depressivas, terminam tomando remédios". (O HOMOSSEXUALISMO..., 2011) Destaca-se somente esta citação, pois a contribuição discursiva poderá ser mais bem apresentada no próximo tópico, ao discutir acerca das relações entre religião, mídia e política.

Na pesquisa de Natividade (2013) a conceituação da homossexualidade como uma doença foi compartilhada entre as pessoas de religiões cristãs, porém, contraditoriamente, houve uma negação da homossexualidade enquanto doença e maldição. Sendo assim, a melhor conceituação da homossexualidade, para as colaboradoras da pesquisa, foi o pecado, pois existe a possibilidade dos dissidentes arrependerem-se e entregarem-se para Jesus. As pessoas que antes disseram que a homossexualidade não era uma doença, também conseguem definir que o 'desejo homossexual' pode ser uma possessão demoníaca, que necessita de uma intervenção ritualística para expurgar o demônio. 
Por mais que muito tem-se discutido somente sobre os homossexuais masculinos, é necessária a inclusão de todas as pessoas que divergem do padrão exigido por estes cristãos deste artigo. O foco dos discursos nos vídeos recaem sobre as bichas e bixas, pois somente eles/as representaram, no entendimento desses cristãos, uma grande ameaça à hegemonia, em debates mais populares. Os ataques, ou discursos de não aceitação, às travestis, transsexuais e lésbicas, por exemplo, não foram percebidos com a mesma expressão.

A partir da leitura de Natividade e Oliveira (2018), pode ser percebido que os homossexuais - para este artigo: todas as dissidências sexuais e de gênero - incitam medo coletivo e pânico moral, por subverterem a cultura compartilhada entre religiosos cristãos. Esta 'ameaça' articula um movimento de produção de 'cidadãos de segunda categoria', tendo como o principal referencial, em posição de superioridade, as pessoas que seguem a cisheteronormatividade.

Entende-se que as articulações de pessoas evangélicas, como exemplifica Tainah Dias (2017), faz com que a 'família' seja uma bandeira de militância. Esta família, que costuma ser protegida pelos/as evangélicos/as, que entendem os dissidentes como uma ameaça, é denominada "por vezes como tradicional, por vezes como natural, e que, como veremos, se pauta em uma concepção de família divina ou sagrada, religiosamente legitimada e postulada como única legítima, excluindo demais arranjos familiares [...]”. (DIAS, 2017, p. 51)

\section{Religiões cristãs: presença na mídia e na política}

O quadro da relação igreja-mídias, em conformidade com Cunha (2019), foi modificado de forma expressiva a partir da dimensão da participação e da transformação dos receptores em emissores, através dos processos de interação possibilitados pela internet, em especial, pelas mídias sociais.

O objetivo das igrejas e dos inúmeros grupos cristãos na pólis midiática, que faz fronteira com o sagrado e com o profano, é de espalhar o evangelho e lhe promover visibilidade. É justamente o que a autora do vídeo Os cristãos e os homossexuais, apresentado no tópico anterior, faz ao introduzir sua gravação, apresentando um material de sua própria autoria com interpretações do Evangelho sobre 'o papel' da mulher no matrimônio: "Tem uma mensagem subliminar ali atrás. Aquele ponto cor de rosa [...] é o meu livro! [...]. Tem um link pro meu blog e você pode adquirir meu livro 'submissa? todos têm um dono"”. (OS CRISTÃOS..., 2014) 
Ainda de acordo com Cunha (2019, p. 13), as "igrejas e grupos cristãos podem firmar comunidade, articular, promover socialidade, expor posições diante de demandas sociais e discuti-las". Por isto que é importante tentar compreender as relações de pessoas de religiões cristãs nos espaços midiáticos:

'É através da mídia - em sua centralidade - que a política é construída simbolicamente, adquire um significado'. (LIMA, 2009, p. 21)

Desta forma, pode-se afirmar que a relação entre evangélicos [e católicos] e política no tempo presente, no Brasil, é marcada pelo processo de midiatização social. (CUNHA, 2019, p. 14)

Considera-se ainda que a mídia não substitui as experiências vividas presencialmente, mas consegue fazer atravessamentos subjetivos entre as pessoas que estão interagindo, mesmo que de forma indireta. As reflexões sobre o espaço midiático, a exemplo desta, fazem emergir, tornar-se nítido, "uma infinidade de articulações e espaços". (CUNHA, 2019, p. 13)

A presença de pessoas de religiões cristãs, em específico da evangélica, nas mídias já foi problematizada por Natividade e Oliveira (2013 apud COELHO, 2017) como um dos principais motivos para uma retomada do conservadorismo brasileiro. Coelho $(2017$, p. 116) explica que existe uma diferenciação: “[...] em relação à estratégia católica seria, em muitos casos, o de discursos explícitos de repúdio à diversidade sexual”.

Contudo, os discursos nem sempre são explícitos; o 'ódio', como na fala a seguir de um padre, pode ser 'deslocado', mas acaba atingindo os mesmos corpos: "Um homossexual não é um gay. Um gay é uma pessoa que está engajada politicamente". (O HOMOSSEXUALISMO..., 2011) Apesar da falha na conceituação e das lacunas encontradas neste vídeo, o padre deixa aparecer uma repulsa por quem é engajado politicamente, e que no raciocínio dele 'está tudo bem' porque ele continua 'amando' os homossexuais - pessoas que não estão nas lutas políticas.

Porém, mesmo existindo diferenças entre as falas de pessoas evangélicas e católicas, esses dois discursos costumam se apresentarem como defensores dos valores cristãos e da família, como já foi discutido no tópico anterior, na tentativa de garantir o conservadorismo.

Magali do Nascimento Cunha (2017) considera que o ativismo político evangélico passa a ser um novo elemento expressivo na relação evangélicos-política, assumindo um caráter de cabos eleitorais dos candidatos em suas respectivas igrejas. Este comportamento digital ganhou maior expressão a partir de 2010, quando estas pessoas começaram a fazer campanhas de oposição aos/às candidatos/as da esquerda, pois os interesses e as ideologias eram divergentes. A autora nos apresenta que o pastor Marco Feliciano conseguiu, com a colaboração de alguns 
políticos, capturar sujeitos para reproduzir suas opiniões acerca do projeto da maioridade penal, em 2015, e do impeachment da presidenta Dilma Rousseff, em 2016.

Porém, ainda demorou um pouco de tempo para a Frente Parlamentar Evangélica ter essa influência. Foi só a partir de 2010 que os parlamentares foram identificados como conservadores do ponto de vista sociopolítico e econômico, com projetos que raramente interferiam no escopo social; as suas atividades e motivos de felicitações, por exemplo, consistiam em barrar os projetos de descriminalização do aborto e do casamento entre duas pessoas do mesmo sexo biológico ou da mesma identidade de gênero. (CUNHA, 2019)

Em 2011, o deputado João Campos, então presidente da Frente Parlamentar Evangélica, propôs uma inclusão na legislação para que as igrejas não fossem obrigadas a realizar as cerimônias de casamento entre homossexuais, que fora reconhecida pelo Supremo Tribunal Federal um pouco antes desta proposta vir a público. João Campos, com suporte de outros políticos, queria evitar possíveis constrangimentos para a religião. Contudo, de acordo com Jean Wyllys, ex-deputado do Rio de Janeiro, esta articulação do João Campos era a fim de confundir a opinião pública, para colocá-la contra o direito civil ${ }^{11}$.

Uma aproximação dos sujeitos deste artigo com os parlamentares evangélicos é a defesa da família cis-heterossexual e monogâmica enquanto bandeira de militância. O vídeo $O$ homossexualismo e a ideologia gay (O HOMOSSEXUALISMO..., 2011) apresentou uma extensa narrativa inquieta com a decisão do Supremo Tribunal Federal de reconhecer a união homoafetiva, a união estável entre pessoas do mesmo sexo. Foi a partir dessa inquietação que o apresentador do vídeo, um padre, fez a diferenciação entre um 'gay' e um 'homossexual', para construir um possível muro onde pudesse excluir quem compactua com políticas inclusivas e até capturar o afeto: "mas esta vitória da ideologia gay significou uma derrota para o homossexual real, concreto e verdadeiro. Aquele rapaz ou aquela moça que você conhece e sabe o drama que ele vive. Sim! O drama real de cada homossexual que é profundamente amado pela igreja”. (O HOMOSSEXUALISMO..., 2011)

$\mathrm{Na}$ construção argumentativa do padre existe uma agenda política ideológica, ou uma ideologia gay, com treinamentos, planejamento e apoio financeiro do governo brasileiro, que tinha Dilma Rousseff como presidenta, e dos governos internacionais, que visa o extermínio do

11 Para mais detalhes da ação da bancada evangélica, em 2011, contra a união entre pessoas do mesmo sexo biológico ou da mesma identidade de gênero, ver: DA REDAÇÃO. Bancada evangélica quer barrar casamento gay em igreja. Exame, São Paulo, 6 maio 2011. Mundo. Disponível em: https://bit.ly/36oN5kH. Acesso em: 25 maio 2020. 
patrimônio cultural e moral do cristianismo. E a captura, ou possível, do afeto dos espectadores midiáticos é feita através dessa mudança hierárquica de dominação/poder, em que não reconhece ou não expressa toda a força das instâncias religiosas cristãs aqui do país, colocando as pessoas LGBTQIA+ no papel de ditadoras, além de recorrer à uma comunicação direta com os 'homossexuais reais': "Nós pedimos, apoiados na palavra de Deus, apoiados no testemunho de Deus, que é Deus encarnado e revelado, não existe felicidade no pecado, o pecado só leva à morte e à destruição... Pare de se machucar”. (O HOMOSSEXUALISMO..., 2011)

Como já dito, o discurso apresentado se aproxima dos discursos dos parlamentares evangélicos que compõem a Frente Parlamentar Evangélica (FPE), como expõe Dias (2017, p. 56, grifo nosso), pois se baseiam “na produção e perpetuação de um discurso de verdade sobre a família tradicional, entendida como monogâmica, heterossexual e patriarcal, e que tem implicações precisas na forma de regular os corpos e a sexualidade dos sujeitos".

As aparições de pessoas que se dizem de religiões cristãs na mídia, bem como os posicionamentos de parlamentares destacados na pesquisa de Dias (2017), para falar sobre alguma questão que atravesse as pessoas LGBTQIA+, é repleta de proibições sexuais, para alcançar uma santidade. No entanto, percebe-se que o sexo passa a ser cada vez mais falado, mesmo sem que as pessoas percebam, e as temáticas de gêneros e sexualidades recebem um espaço central no plano discursivo. Dias (2017), a partir da perspectiva foucaultiana, considera que não há problema em discutir sobre as diversas temáticas, mas deve-se ter cuidado para com as produções e reproduções de discursos de verdade, pois, como na concepção de Judith Butler (2015 apud DIAS, 2017), as verdades sobre a sexualidade tornam algumas ininteligíveis.

É nesse sentido que os discursos de verdade, apresentados por Michel Foucault ao longo de suas obras, representam relevância neste trabalho, pois o filósofo considera que "não é simplesmente aquilo que manifesta (ou oculta) o desejo; é também aquilo que é o objeto do desejo [...] não é aquilo que traduz as lutas ou os sistemas de dominação, mas aquilo por que, pelo qual se luta, o poder do qual nos queremos apoderar". (FOUCAULT, 1996, p. 10)

Existe um discurso de verdade sobre a família, tendo o matrimônio monogâmico entre homens e mulheres cis como base, que é compartilhado pela extensão do território brasileiro, produzido e legitimado por uma forma de poder normalizador no campo religioso, que "é corroborado com a tentativa de institucionalização jurídica de um discurso de verdade sobre a família, em forma de lei, e é perpassada por este poder e por este discurso que procuram estabelecer a legitimidade da configuração tradicional de família”. (DIAS, 2017, p. 65, grifo 
nosso) Ou seja, todas as articulações, da instância pessoal, social, religiosa e política, é em nome da família heteronormativa.

Dias (2017) destaca em sua pesquisa que estas verdades hegemônicas sobre família como sendo composta através do matrimônio monogâmico entre homens e mulheres cis surgiram, principalmente, nos discursos dos séculos XVIII e XIX, produzindo, ao mesmo tempo, 'verdades' para as sexualidades e identidades 'periféricas' ou 'contra natureza'. Esta estrutura ainda pode ser visualizada nas atuais configurações deste novo século e é problemática, pois concebe um 'natural', um padrão, em detrimento e superioridade ao 'não natural', às/aos dissidentes. Dessa forma, como já discutido no primeiro tópico deste artigo, a cisheteronormatividade ganha um espaço de privilégio, devendo ser assegurada e protegida.

Ao realizar uma breve busca ou um regaste na memória das grandes personalidades políticas brasileiras, mas não somente, observou-se uma repetição aproximada de: homens, brancos, cisgêneros, heterossexuais e que defendem os 'bons costumes' fundamentados pela leitura literal e fundamentalista da bíblia. Esta repetição pode ser o que não torna este novo século tão diferente dos últimos, em questões acerca de gêneros e sexualidades. Além de não se descolar de um traço colonial. Michel Foucault (1999) observa que não é qualquer corpo que pode dominar o discurso, é necessário ter a autorização para falar. O filósofo ainda desenvolve que "ninguém entrará na ordem do discurso se não satisfizer certas exigências ou se não for, de início, qualificado para fazê-lo". (FOUCAULT, 1999, p. 37)

Nesse sentido, os discursos desses homens apresentados anteriormente são considerados como verdades absolutas, a partir de uma necessidade da ordem do discurso, de uma hierarquização. É importante salientar que já não mais observamos atuações sociais isoladas, delimitando cada pessoa ao seu espaço comum, como por exemplo um padre ou pastor na igreja, uma pessoa política em lugares que exigem uma grande formalidade devido aos debates que não 'devem' ser entendidos pela população, e um comunicador que compartilha seu trabalho através de diversos tipos de telas.

Atualmente, observa-se que são as pessoas autorizadas à fala que exercem várias funções e estão nos diversos lugares. Então, o pastor ou padre, ou qualquer outra figura que tem influência religiosa, também pode ser um representante político e fazer uso das plataformas digitais para falar de maneira 'pessoal' e/ou 'profissional', sabendo que não existe, necessariamente, uma fronteira palpável desta diferenciação. Sendo assim, estabelecem-se: 
[...] procedimentos de controle e de delimitação do que é enunciado e de procedimentos de exclusão daquilo que coloca em jogo o poder e o desejo. Os discursos que se proliferam e ecoam na sociedade devem, segundo Foucault, responder a determinadas condições específicas, e evidenciam-se, por exemplo, na organização de disciplinas. (DIAS, 2017, p. 57)

\section{LGBTQIAfobia e subjetividades dissidentes}

Para discutir os atravessamentos subjetivos, em específico as violências simbólicas, que os discursos de pessoas religiosas causam em pessoas LGBTQIA+, é fundamental compreender o termo e as práticas LGBTQIAfóbicas, pois a homofobia, especificamente, é, de acordo com Santos, Araujo Neves e Neves (2017), em suma, um preconceito e uma discriminação às pessoas homossexuais $^{12}$. Dessa forma, a LGBTQIAfobia neste tópico será visualizada próxima às filosofias e práticas cristãs.

Inicialmente, é necessário afirmar, com base no que já foi e no que será exposto a seguir, que as pessoas não têm as mesmas demandas, os grupos são desiguais, e as pessoas que se articulam com a cis-heterossexualidade passam por questões distintas das outras pessoas. Isto difere do discurso hegemônico encontrado na coleta deste artigo que assegura que "todos temos os mesmo problemas”. (A RELIGIÃO..., 2019)

Logo nos momentos iniciais do vídeo Os cristãos e os homossexuais, escuta-se: "Acredito que práticas homossexuais sejam pecados. Ponto. Só um ponto. Agora se eu tenho amigos homossexuais? Tenho. E alguns muitos queridos, muitos amáveis e muitos divertidos.” (OS CRISTÃOS..., 2014) Assim como já discutido ao longo da fundamentação deste estudo, Santos, Araujo Neves e Neves (2017) explicam que a igreja cristã colaborou com a promoção da cis-heterossexualidade monogâmica como norma, sendo possível apenas pela rejeição das práticas homossexuais, dissidentes, colocando-as no escopo pecaminoso tal como o canibalismo, a bestialidade ou 'ingestão de imundices'.

A autora do vídeo citado anteriormente destaca que apoia os homossexuais, assim como qualquer outro ser humano, mas ainda os considera pecadores. (OS CRISTÃOS..., 2014) Nesse

12 A empregabilidade do termo 'homofobia' ainda foi considerada em alguns momentos deste tópico, pois foi extraído dos estudos referenciais, que tinham os seus devidos recortes populacionais e temporais. Além de observarmos que os discursos coletados referem-se, na maioria das vezes, apenas aos homossexuais masculinos. Porém, pode-se maximizar este pensamento, a fim de considerar todas as pessoas que divergem da cisheteronormatividade, e não apenas os homossexuais masculinos, e ainda perceber que as discussões em torno da LGBTQIAfobia podem ter uma enorme variabilidade. 
mesmo sentido, uma entrevistada relata em um programa televisivo de cobertura nacional e com propagação disponível nas mídias digitais, dentre elas o YouTube, que:

Eu acho que o pecado é algo abominável e ele distancia a gente de Deus. Mas amo as pessoas que escolheram viver assim dessa forma, né. Tem a sua opção, a sua escolha. e... o meu coração sempre vai tá aberto pra liberar amor, pra liberar essa fonte de amor que é Jesus [...]. (NÃO CONCORDO..., 2018, grifo nosso)

É importante ressaltar que este discurso citado foi proferido por Aline Barros, que é uma referência na música gospel. Em 1990, por exemplo, a cantora teve a sua primeira música gravada por 45 dias no topo das rádios evangélicas da cidade do Rio de Janeiro. A partir de então, o seu alcance extrapolou as delimitações estadual, regional e nacional, lhe permitindo espaço para apresentar programas televisivos e parcerias com outras grandes personalidade brasileiras, a exemplo de Xuxa Meneghel ${ }^{13}$. O vídeo de sua entrevista foi publicado em abril de 2018, pelo canal da RedeTV, e está com 176.028 visualizações.

Conforme Borrillo:

Os elementos precursores de uma hostilidade contra lésbicas e gays emanam da tradição judaico-cristã [...] Por sua vez, o cristianismo, ao acentuar a hostilidade da Lei judaica, começou por situar os atos homossexuais - e, em seguida, as pessoas que os cometem não só fora da Salvação, mas também e, sobretudo, à margem da Natureza. O cristianismo triunfante transformará essa exclusão da natureza no elemento precursor e capital da ideologia homofóbica. [...] A desumanização foi, assim, a conditio sine qua non da inferioridade, da segregação e da eliminação dos 'marginais em matéria de sexo’. (BORRILLO, 2015 apud SANTOS; ARAUJO NEVES; NEVES, 2017, p. 441)

Já houve avanços em diversas agendas políticas e colaborações do corpo social interessados em erradicar os modos impositivos que acometem as pessoas em situações vulneráveis, seja de forma física e/ou simbólica. No entanto, a diversidade de gênero e de sexualidade ainda é encarada como 'contagiosa' em muitos espaços de interação, a exemplo da escola e da própria pólis midiática, promovendo, assim, uma marginalização das pessoas dissidentes. (SANTOS; ARAUJO NEVES; NEVES, 2017)

Entendendo a homofobia como um fenômeno complexo e plural, ainda de acordo com as autoras e o autor citadas/o anteriormente, existe a homofobia geral, que pode ocorrer quando

13 Para mais informações sobre Aline Barros, ver: BARROS, A. Aline Barros, 2020. Rio de Janeiro. Biografia. Disponível em: https://bit.ly/33x7fXZ. 
homens apresentam características que o social entende como feminino; existe a homofobia individual, sendo demarcada pelo duplo preconceito contra o gênero feminino e a sexualidade; a homofobia afetiva, ressaltando principalmente o caráter psicológico das condenações à diversidade; e a homofobia cognitiva, que atua no campo social, perpetuando as diferenças entre cis-heterossexualidade e as homossexualidades, e todas as formas diversas.

O objetivo desta discussão não é a de esgotar todas as apresentações das complexidades da homofobia, por isto destacam-se as contribuições de Natividade e Oliveira (2009) ao estudarem a homofobia presente nos discursos religiosos. A homofobia religiosa, por exemplo, é caracterizada como "práticas e discursos que se baseiam em valores religiosos que operam por meio de táticas plurais e polimorfas de desqualificação e controle da diversidade sexual". (NATIVIDADE; OLIVEIRA, 2009, p. 132, grifo nosso) Esta definição pode ser exemplificada com a seguinte elaboração:

A igreja não discrimina os homossexuais. E por que isso? Por uma razão muito simples. Veja. O sexo é uma realidade sagrada. Assim como a raça é uma realidade sagrada. Veja, a raça negra, branca, pardo, amarelo, mestiço, mulato é algo desejado por Deus. É algo que não deve ser alterado, não deve ser tocado. É sagrado assim também o sexo. Homem ou mulher foi algo criado por Deus e não deve ser tocado. É algo sagrado. É por isso que a igreja diz que os homossexuais devem mudar a sua conduta, seu comportamento. Exatamente, porque não tem cabimento a gente sacralizar a raça e não sacralizar o sexo. Como algo desejado e querido por Deus. (A IGREJA..., 2015)

Este vídeo, assim como o CGRP, foi publicado pelo Padre Paulo Ricardo em seu canal do YouTube, e tem como título A Igreja Católica discrimina os homossexuais? (A IGREJA..., 2015), publicado em março de 2015, e está com 111.640 acessos. De acordo com a narrativa do padre, percebe-se uma comparação entre questões sexuais e com a raça/etnia para explicar que a igreja, no caso a católica, não discrimina os homossexuais, com fundamentação em valores religiosos. Esta comparação equivocada se estendeu ao longo do vídeo e foi concluída da seguinte maneira: “[...] essas pessoas devem ser acolhidas no tecido da sociedade como ninguém deveria discriminar o Michael Jackson porque, teoricamente, quis mudar de raça. Nós não estamos concordando com o que ele fez, mas não vamos discriminá-lo”. (A IGREJA..., 2015)

Dessa forma, segundo Natividade (2013), a homofobia religiosa é multifacetada e apresenta uma de suas face ao proliferar os discursos sobre a cura da homossexualidade, através da não aceitação das expressões e identificações das/os dissidentes, bem como o discurso que o vídeo citado apresenta em seu desenvolvimento. 
Em linhas gerais, este tipo de homofobia não se demonstra tão violento como os outros, porque não apresenta, necessariamente, um risco iminente de violência física. Ao contrário de violências corporais e expressões discursivas de ódio e repulsa, as pessoas, especificamente as que são evangélicas, conseguem fazer um acolhimento dos sujeitos dissidentes: "porque ninguém mais, nesse país, ama os homossexuais do que a igreja" (O HOMOSSEXUALISMO..., 2011) e "precisamos dar abrigo e acolhida para os homossexuais dentro da igreja, convidando-os a viver a castidade que é o único caminho de santificação”. (O HOMOSSEXUALISMO..., 2011, grifo nosso)

Este acolhimento, de acordo com Natividade (2013), é problemático pois pode ser visto como uma estratégia política higienista, que a todo momento antagoniza e desqualifica sexualidades e identidades consideradas indesejáveis. Marcelo Natividade e Leandro de Oliveira (2018) conseguem, a partir da perspectiva de acolhida da diversidade sexual, objetivando a cura através do aconselhamento, indicar possíveis processos de sujeição e estigmatização das vidas que são contra hegemônicas, pois sempre as colocam em posição cristalizada de, não no sentido de nobreza, inferioridade. Então, as ações de 'dar abrigo e acolher' e 'convidar' uma pessoa para viver a castidade podem ser interpretadas como ações que desqualificam as sexualidades e identidades dissidentes.

Destaca-se aqui, assim como Natividade (2013), o não apontamento ou julgamento de uma expressão lógica de que pessoas cristãs são, essencialmente, homofóbicas. Ou, até, de que pessoas que reproduzem falas e comportamentos homofóbicos também sejam homofóbicas. Há uma grande diferença entre 'ser' e 'estar', e é justamente por isto que este artigo não objetiva-se em fazer acusações deste cunho.

As seguintes afirmações foram realizadas por pessoas que consideram a homossexualidade um pecado e ilustram a complexidade, o caráter ambíguo: "A questão é que se você é cristão, você 'num' tá seguindo a Cristo discriminando, rejeitando uma pessoa, porque ela vive de um modo diferente". (OS CRISTÃOS..., 2014) e "Uma coisa é ser contra o comportamento homossexual. Outra coisa é ser contra o homossexual em si. Se um cristão é contra o homossexual em si, ele não é um cristão verdadeiramente convertido". (A RELIGIÃO..., 2019) Nota-se, como dito, uma relação limítrofe entre declarações de repulsa e acolhimento, assim como pode ser percebido em outros relatos apresentados nos últimos tópicos discursivos.

Pode parecer complexo, no entanto, o importante é compreender que essas práticas e 
discursos dizem respeito mais a performances do que identidades, tornando-as contingenciais e situacionais. Esta perspectiva pode se aproximar de uma romantização das violências, mas abre possibilidades de mudanças epistemológicas e práticas.

\section{Considerações finais}

O artigo buscou articular a discussão sobre diversidade sexual e de gênero na concepção de pessoas que se aproximam, através do discurso, da cis-heteronormatividade e das religiões cristãs no território brasileiro. Para tanto, foi feita uma análise do discurso de vídeos disponibilizados no YouTube a fim de buscar os efeitos de sentido que se pode apreender mediante a interpretação, em que foram evidenciadas três categorias de análise: 1. a cisheteronormatividade: regulação de saberes e práticas; 2. religiões cristãs: presença na mídia e na política; e 3. LGBTQIAfobia e subjetividades dissidentes.

Conferiu-se visibilidade ao fato de que as características exclusivamente biológicas ainda conseguem definir e determinar os modos de existências das pessoas, sendo contrário à ideia de que o gênero, em específico, é uma construção social. Foi possível perceber, através dos discursos extraídos dos vídeos selecionados, que predomina uma concepção normativa de expressões identitárias, o que endossa o funcionamento social cis-heteronormativo.

Os vídeos selecionados ainda foram produzidos a partir de uma leitura literal e fundamentalista da Bíblia, do Evangelho, que precede a possibilidade de divulgar estes materiais na internet. Ou seja, trata-se de interpretações já formuladas durante seus processos pessoais e coletivos formativos que são divulgadas na pólis midiática como verdades absolutas e inquestionáveis. Estas leituras literais, que às vezes buscam suporte na legislação, podem aumentar as chances de uma retomada do conservadorismo brasileiro.

Além disso, a contradição presente nos discursos aqui analisados, faz questionar como os acolhimentos das pessoas LGBTQIA+ são feitos por pessoas que se aproximam da cisheteronorma e dos saberes e práticas do cristianismo. No entendimento dos sujeitos que se apresentaram cristãos, 'os pecadores' têm de trilhar caminhos para o encontro com Deus. Ou seja, as pessoas LGBTQIA+ são desqualificadas e controladas, pois devem 'suspender' suas performances de gênero e sexualidade.

Espera-se que este artigo motive a realização de outros, revelando os 'lugares' de pessoas cristãs na luta para a garantia de direitos civis das pessoas que não seguem as normativas da cis- 
heterossexualidade e, sobretudo, dos seus direitos de existências. Também vale ressaltar que os discursos aqui analisados não representam, de fato, uma religião; como foi discutido, os discursos partem de interpretações que sempre são passíveis de equívocos.

Isto posto, é importante pontuar as limitações deste texto. Como a internet é um espaço dinâmico, bem como o YouTube, as discussões não conseguem se manter do mesmo jeito por muito tempo. Os diálogos sobre gênero e sexualidade também sofrem variações, pois se alinham com a própria diversidade das existências dos indivíduos. Os vídeos analisados neste artigo estavam em evidência no YouTube em um período específico, podendo ser por uma semana, um mês ou por um ano. É possível surgir alterações discursivas e interpretativas. O que vai, de alguma forma, determinar essas nuances é a própria relação entre religiões cristãs, mídia e política em um determinado contexto social.

\section{Referências}

A IGREJA Católica discrimina os homossexuais? [S. l.: s. n.], 2015. 1 vídeo (6 min). Publicado pelo canal Padre Paulo Ricardo. Disponível em: https://bit.ly/3lzs4bu. Acesso em: 12 abr. 2020.

A RELIGIÃO e a Bíblia são contra os LGBT? [S. l.: s. n.], 2019. 1 vídeo (14 min). Publicado pelo canal Leandro Quadros. Disponível em: https://bit.ly/37nAHR7. Acesso em: 12 abr. 2020.

ALEXANDRE, R. Afinal, quem são "os evangélicos"? Carta Capital, São Paulo, 7 set. 2014. Sociedade. Disponível em: https://bit.ly/3obrCSj. Acesso em: 28 maio 2020.

ANTUNES, D. C. A dialética do feminino em Theodor W. Adorno ou: "a própria mulher é já o efeito do chicote"? Cult, São Paulo, v. 1, n. 215, p. 24-26, 2016.

BRASIL. Lei $\mathrm{n}^{\circ}$ 12.527, de 18 de novembro de 2011. Regula o acesso a informações previsto no inciso XXXIII do art. $5^{\circ}$, no inciso II do $\S 3^{\circ}$ do art. 37 e no $\S 2^{\circ}$ do art. 216 da Constituição Federal; altera a Lei ${ }^{\circ} 8.112$, de 11 de dezembro de 1990; revoga a Lei $\mathrm{n}^{\circ} 11.111$, de 5 de maio de 2005, e dispositivos da Lei $\mathrm{n}^{\circ} 8.159$, de 8 de janeiro de 1991; e dá outras providências. Diário Oficial da União, Brasília, DF, 18 nov. 2011.

CAREGNATO, R. C. A.; MUTTI, R. Pesquisa qualitativa: análise de discurso versus análise de conteúdo. Texto contexto: Enfermagem, Florianópolis, v. 15, n. 4, p. 679-684, 2006.

COELHO, F. M. F. As novas guerras sexuais: diferença, poder religioso e identidade LGBT no Brasil. Mandrágora, São Bernardo do Campo, v. 23, n. 1, p. 113-123, 2017. 
CUNHA, M. N. Do púlpito às mídias sociais: evangélicos na política e ativismo digital. Curitiba: Prismas, 2017.

CUNHA, M. N. Os processos de midiatização das religiões no Brasil e o ativismo político digital evangélico. Revista Famecos, Porto Alegre, v. 26, n. 1, p. 30691, 2019.

DIAS, T. B. Sobre religião, estado laico e cidadania $L G B T+$ : a frente parlamentar evangélica brasileira e a defesa da verdade sobre a família. 2017. Dissertação (Mestrado em Ciências da Religião) - Faculdade de Teologia, Universidade Metodista de São Paulo, São Bernardo do Campo, 2017.

EXISTE "cura gay"? Padre Paulo Ricardo responde. [S. l.: s. n.], 2018. 1 vídeo (13 min). Publicado pelo canal Padre Paulo Ricardo. Disponível em: https://bit.ly/3qh7xMj. Acesso em: 12 abr. 2020.

FOUCAULT, M. A ordem do discurso: aula inaugural no Collège de France. 7. ed. São Paulo: Loyola, 1996.

LEANDRO Quadros. San Bruno: YouTube, 2009. Disponível em: https://bit.ly/3oasOoY. Acesso em: 6 jan. 2021.

MATTOS, A. R.; CIDADE, M. L. R. Para pensar a cisheteronormatividade na psicologia: lições tomadas do transfeminismo. Periódicus, Salvador, v. 1, n. 5 , p. 132-153, 2016.

"NÃO CONCORDO com as práticas", diz Aline Barros sobre homossexualidade. [S. l.: s. n.], 2018. 1 vídeo ( $2 \mathrm{~min}$ ). Publicado pelo canal RedeTV. Disponível em: https://bit.ly/3qlgF2e. Acesso em: 12 abr. 2020.

NATIVIDADE, M. T. Homofobia religiosa e direitos LGBT: notas de pesquisa. Latitude, Maceió, v. 7, n. 1, p. 33-51, 2013.

NATIVIDADE, M.; OLIVEIRA, L. Sexualidades ameaçadoras: religião e homofobia(s) em discursos evangélicos conservadores. Sexualidad, Salud y Sociedad, Rio de Janeiro, n. 2, p. 121-161, 2009.

NATIVIDADE, M.; OLIVEIRA, L. As novas guerras sexuais: diferença, poder religioso e identidades LGBT no Brasil. Rio de Janeiro: Garamond, 2018.

O HOMOSSEXUALISMO e a ideologia gay. [S. l.: s. n.], 2011. 1 vídeo (17 min). Publicado pelo canal Padre Paulo Ricardo. Disponível em: https://bit.ly/2JquQmb. Acesso em: 12 abr. 2020.

OS CRISTÃOS e os homossexuais. [S. l.: $s . \quad n.], 2014.1$ vídeo (6 min). Publicado pelo canal Fabiana Bertotti. Disponível em: https://bit.ly/2Vobvo1. Acesso em: 12 abr. 2020.

PADRE Paulo Ricardo. San Bruno: YouTube, 2010. Disponível em: https://bit.ly/33znOCn. Acesso em: 6 jan. 2020.

PELLEGRINI, D. P. et al. YouTube: uma nova fonte de discursos. Biblioteca On-line de Ciências da Comunicação, Covilhã, v. 1, n. 1, p. 1-8, 2009.

SANTOS, L. P.; ARAUJO NEVES, H.; NEVES, R. A. Interferências das crenças religiosas no combate da homofobia na escola. In: CONGRESSO 
LATINO-AMERICANO DE GÊNERO E RELIGIÃO, 5., 2017, São Leopoldo. Anais [...]. São Leopoldo: EST, 2017. p. 439-455.

SILVA, J. C.; PEREIRA, J. D. S.; PONTES, N. L. M. T. "Ser um homem feminino...": identidade e afeminofobia de masculinidades de homens gays. In: SEMINÁRIO INTERNACIONAL DESFAZENDO O GÊNERO, 4., 2019, Campina Grande. Anais [...]. Campina Grande: Realize, 2019. p. 1-12. Disponível em: https://bit.ly/2VnChgf. Acesso em: 4 maio 2020.

VEIGA, L. As diásporas da bixa preta: sobre ser negro e gay no Brasil. Tabuleiro de Letras, Salvador, v. 12, n. 1, p. 77-88, 2018. Disponível em: https://bit.ly/3980YDV. Acesso em: 6 jan. 2021.

YOUTUBE. YouTube em números: mais de dois bilhões de usuários. San Bruno: YouTube, 2020. Disponível em: https://bit.ly/33yfanD. Acesso em: 23 maio 2020. 